\title{
The Effectiveness of Clinical Guidelines in the Diagnosis of Lynch Syndrome Compared to Microsatellite Instability and Immuno- histochemistry Analyses in Southern Thailand
}

Thitipat Thavornpattanapong, M.D. ${ }^{1}$ Kanet Kanjanapradit, M.D. ${ }^{2}$, Surasak Sangkhathat, M.D., Ph.D. ${ }^{1}$, Worrawit Wanitsuwan, M.D. ${ }^{1}$

'Department of Surgery, Faculty of Medicine, Prince of Songkla University, Hat Yai, Songkhla 90110, Thailand.

2Department of Pathology, Faculty of Medicine, Prince of Songkla University, Hat Yai, Songkhla 90110, Thailand.

Received 12 September 2018 • Revised 11 December 2018 • Accepted 18 December 2018 • Published online 18 January 2019

\section{Abstract:}

Objective: This study aims to assess the accuracy of Amsterdam II criteria (AMII) and Revised Bethesda Guidelines (RBG) compared to molecular tests in Thai patients.

Material and Methods: One hundred eighty-one patients were enrolled. Demographic data and pathological features and locations of tumors were recorded. Family history of the patients was reviewed by AMII and RBG. Tissue samples were collected and molecular testing was tested by microsatellite instability (MSI) analysis and immunohistochemistry $(\mathrm{IHC})$. Statistical analysis was used to estimate the sensitivity and specificity of AMII and RBG compared to molecular testing.

Results: Of the patients, $2.8 \%$ fulfilled the AMII criteria and $28.1 \%$ met the RBG criteria. Molecular testing showed $16.57 \%$ and $13.8 \%$ of the samples lost at least 1 out of 4 mismatch repair (MMR) proteins in the IHC test. In addition, $10.5 \%$ of patients had both microsatellite instability high $(\mathrm{MSI}-\mathrm{H})$ and loss of protein MMR expression. The sensitivity and specificity of AMII were $6.7 \%$ and $98.0 \%$, respectively, while for the RBG they were $70.0 \%$ and $82.1 \%$, respectively.

Conclusion: The present study suggests that for patients who complete the AMII, doctors should be highly suspicious of Lynch syndrome, due to its high specificity. The RBG is useful for screening for Lynch syndrome and the selection of individuals for further molecular testing.

Keywords: accuracy, hereditary non-polyposis colorectal cancer (HNPCC), Lynch syndrome, mismatch repair gene, $\mathrm{MSI}$ analysis

Contact: Asst. Prof. Worrawit Wanitsuwan, M.D.

Department of Surgery, Faculty of Medicine, Prince of Songkla University,

Hat Yai, Songkhla 90110, Thailand.

E-mail: worawitwanich@gmail.com
J Health Sci Med Res 2019;37(1):43-50 doi: $10.31584 /$ jhsmr.201938 www.jhsmr.org 


\section{Introduction}

Colorectal cancer $(\mathrm{CRC})$ is one of the leading causes of cancer-related death worldwide. ${ }^{1}$ In Songklanagarind Hospital, 326 patients were diagnosed with CRC in 2010, out of a population of 195,287 new patients. The majority of cases are sporadic with various factors including genetics, environment and lifestyle. However, in approximately 5.0$10.0 \%$ cases genetic factors play a dominant role in CRC development. The most common inherited CRC is Lynch syndrome, also known as hereditary non-polyposis colorectal cancer (HNPCC), with a 3.0-8.0\% incidence of all $\mathrm{CRC}$ cases. ${ }^{2}$ Lynch syndrome is characterized by an autosomal dominant gene, the early onset of CRC and an increase in life-time risk of other cancers. ${ }^{3}$ The evidence supports that colonoscopic surveillance in individuals with Lynch syndrome should reduce the morbidity and mortality. ${ }^{4}$ Lynch syndrome is caused by a germline mutation in mismatch repair (MMR) genes. The most notable are human mutL homolog 1 (MLH1), human mutS homolog 2 (MSH2), human mutS homolog 6 (MSH6) and postmeiotic Segregation Increased, S. Cerevisiae, 2 (PMS2)..$^{5-8}$ Identification of a gene defect is often recommended in order to confirm the diagnosis; however, it is not practical for every CRC patient due to the high cost and the complicated process. Currently, Amsterdam II criteria (AMII) and Revised Bethesda Guidelines (RBG) have been recommended for screening individual suspected of Lynch syndrome. ${ }^{9-12}$ Previous studies indicated that both the AMII and RBG have low a sensitivity of $40.0 \%$ and 90.0\%, respectively. ${ }^{10,13-15}$ However, these two parameters have not been evaluated in Thailand, which could lead to the appropriate application of both guidelines to Thai patients.

The present study was designed to assess the effectiveness of the AMII and RBG related to the results of molecular tests [microsatellite instability (MSI) analysis and immunohistochemistry (IHC)] and to investigate the prevalence of Lynch syndrome at Songklanagarind Hospital, with the aim of establishing suitable clinical practice guidelines for screening for Lynch syndrome in Southern Thailand.

\section{Material and Methods}

\section{Sample size and patients}

The present study was approved by the Research Ethics Committee of the Faculty of Medicine, Prince of Songkla University. The sample size was calculated based on the sensitivity and specificity of the previous studies. ${ }^{10,13-15}$ A minimum 154 samples were used in this study with an acceptable accuracy [95\% confidence interval $(\mathrm{Cl})$ ]. CRC patients who were diagnosed between January 2012 and February 2013 and underwent operations at Songklanagarind Hospital were included. Exclusion criteria included patients with unclear family histories, with evidence of familial adenomatous polyposis syndrome and with preoperative chemoradiotherapy in which the residual tissue was not sufficient for molecular testing. The demographic data, family history and clinical features of patients were reviewed and collected from the out-patient department. The tumors in paraffin-bedded tissue were collected and reviewed. The controlled samples were taken from peripheral blood or normal mucosa tissue.

\section{Clinical guidelines}

The well-known criteria of screening for Lynch syndrome are the AMII and RBG. ${ }^{13,15}$ The AMII consists of the following: (1) At least three relatives with colorectal cancer or Lynch syndrome-associated cancer, such as cancer of the endometrium, small bowel, stomach, pancreas, biliary tract, brain, ureters and renal pelvis. (2) One relative should hold a first-degree relative of the other two. (3) At least two successive generations should be affected. 
(4) At least one tumor should be diagnosed before the age of 50 years. All criteria must be fulfilled. On the other hand, one of the RBG suggests that the individual should be selected for molecular testing for the diagnosis of Lynch syndrome. The RBG criteria are composed of (1) a patient younger than 50 years old diagnosed with colorectal cancer. (2) Presence of synchronous, metachronous colorectal or other Lynch-related tumors, regardless of age. (3) Colorectal cancer with microsatellite instability high (MSI-H) phenotype diagnosed in a patient younger than 60 years old. (4) A patient with colorectal cancer and a firstdegree relative with a Lynch syndrome-related tumor, with one of the relatives being diagnosed with colorectal cancer at an age younger than 50 years old. (5) A patient with colorectal cancer with two or more first- or second-degree relatives with Lynch syndrome-related tumor, regardless of age.

\section{Microsatellite instability analysis}

The histologic features of tumors were reevaluated for adequate tumor cells. All samples covered more than a $50.0 \%$ proportional area of the tumor cells. The deoxyribonucleic acid (DNA) from the tumor tissue and adjacent normal tissue were purified using the QIAamp tissue kit (QIAGEN, Germany). DNA was amplified using a polymerase chain reaction (PCR) (QIAGEN toptaq DNA polymerase, Germany). Yields and purity were determined by electrophoresis on agarose gel and spectrophotometric absorbance at 260 nanometer. The results were analyzed by Genescan analysis software. Five reference microsatellite markers: D5S345, D2S123, BAT25, BAT26, and D17S250 were applied to determine $\mathrm{MSI}^{16}$ The primer sequences were obtained from GenBank. MSI analysis was performed by comparing normal and tumor tissue. If two or more of the markers shifted in size and location, they were classified as having microsatellite instability. ${ }^{17,18}$

\section{Immunohistochemistry}

The IHC for MLH1, MSH2, MSH6 and PMS2 was performed using mouse monoclonal anti-MLH1, MSH2, MSH6 and PMS2 antibodies (Abcam, USA). Negative control slides were conducted without the primary antibody. Absent staining refers to MMR mutation. The criteria for loss of MMR protein expression consist of intensity score and proportion score. The intensity score was classified as negative $(0)$, weak $(+1)$, moderate $(+2)$ and strong $(+3)$; weak positive was also counted as a positive sample. The proportion score was based on area of staining. If it was less than $10.0 \%$ of protein expression, this referred to a loss of MMR protein expression. The results were confirmed by two blinded certificated pathologists.

\section{Data analysis}

Patient demographic data and clinical features were reported as mean or median. Categorical variables were analyzed using a chi-square test, and Student's t-test was employed to compare quantitative variables between groups. P-value $<0.05$ for a 2 -tailed test was considered significant. The accuracy of AMII and RBG were demonstrated in sensitivity and specificity. Statistical analysis was calculated based on program $R$ version 2.15.1.

\section{Results}

Four hundred twenty-two patients were recruited from the Songklanagarind Hospital cancer registration records between $1^{\text {st }}$ January 2012 and $28^{\text {th }}$ February 2013, with 205 patients having undergone colorectal operations. Twenty-four patients were excluded: three patients due to their clinical history of familial adenomatous polyposis (FAP), five patients due to post chemoradiation and inadequate tissue for molecular testing. The other 16 patients were excluded because of the unavailability of both a clinical history and tissue specimen. A total 181 patients 
were enrolled in the present study. Mean age was $61.8 \pm$ 14.5 years (range, 19-89). There were 95 men (52.5\%) and 86 women (47.5\%). There were 39 right-sided tumors (21.5\%) and 142 left-sided tumors (78.5\%). The mean length of a specimen was $21.5 \pm 13.1$ centimeter. Almost all the specimens were adenocarcinomas. The patients were classified by tumor, nodes, and metastases (TNM) staging: stage I, 16 (8.8\%), stage II, 63 (34.8\%), stage III, 56 (30.9\%) and stage IV, 46 (25.4\%) (Table S1).

Table S1 Pathological features of patients in this study

\begin{tabular}{ll}
\hline Characteristics & Number of \\
patients $(\%)$
\end{tabular}

Table S1 (continued)

\begin{tabular}{|c|c|}
\hline Characteristics & $\begin{array}{l}\text { Number of } \\
\text { patients (\%) }\end{array}$ \\
\hline \multicolumn{2}{|l|}{ Resection margin } \\
\hline Free margin & $175(96.7)$ \\
\hline Microscopic & $6(3.3)$ \\
\hline \multicolumn{2}{|l|}{ Total node examined } \\
\hline Mean (S.D.) & $22.4(17.8)$ \\
\hline \multicolumn{2}{|l|}{ Metastasis node } \\
\hline Mean (S.D.) & $2.7(4.8)$ \\
\hline \multicolumn{2}{|l|}{ Metastasis site } \\
\hline No metastasis & $134(74)$ \\
\hline Liver & $16(8.8)$ \\
\hline Lung & $4(2.2)$ \\
\hline Peritoneum & $3(1.7)$ \\
\hline Non regional node & $2(1.1)$ \\
\hline More than one & $22(12.2)$ \\
\hline \multicolumn{2}{|l|}{ Primary tumor $\mathrm{T}$ staging } \\
\hline $\mathrm{T} 1$ & $4(2.2)$ \\
\hline T2 & $18(9.9)$ \\
\hline T3 & $112(61.9)$ \\
\hline T4a & $18(9.9)$ \\
\hline $\mathrm{T} 4 \mathrm{~b}$ & $29(16.0)$ \\
\hline \multicolumn{2}{|l|}{ Node staging } \\
\hline$N X$ & $1(0.6)$ \\
\hline No & $82(45.3)$ \\
\hline N1a & $23(12.7)$ \\
\hline N1b & $30(16.6)$ \\
\hline N1c & $1(0.6)$ \\
\hline $\mathrm{N} 2 \mathrm{a}$ & $20(11.0)$ \\
\hline $\mathrm{N} 2 \mathrm{~b}$ & $24(13.3)$ \\
\hline \multicolumn{2}{|l|}{ Distant metastasis } \\
\hline No metastasis & $136(75.1)$ \\
\hline Metastasis & $45(24.9)$ \\
\hline \multicolumn{2}{|l|}{ TNM staging } \\
\hline I & $16(8.8)$ \\
\hline II & $63(34.8)$ \\
\hline III & $56(30.9)$ \\
\hline IV & $46(25.4)$ \\
\hline
\end{tabular}

S.D.=standard deviation, $\mathrm{G}=$ grading, $\mathrm{T}=$ tumor, $\mathrm{N}=$ nodes, TNM=tumor, nodes, and metastases staging 
Both MSI analysis and IHC were employed to determine tumor MMR testing in 181 patients. Of the 181 patients, $30(16.57 \%)$ were classified as MSI-H and $14(7.73 \%)$ as microsatellite instability low (MSI-L). The most common MSI markers were BAT25 and D2S132, which were found in 23 out of $44 \mathrm{MSI}$ tumors (52.3\%). Meanwhile, through the $\mathrm{IHC}$ analysis, there were 25 tumors (13.8\%) that lost MMR protein expression: MLH1, MSH2, MSH6 and PMS2 $56.0 \%, 16.0 \%, 28.0 \%$ and $68.0 \%$ respectively. Also, there were 19 tumors (10.5\%) with $\mathrm{MSI}-\mathrm{H}$ and loss of MMR protein expression.

Five patients (2.8\%) fulfilled the AMII. All of them were classified as MSI-H and lost MMR protein expression based on the IHC method (Table S2, 1 and 2). The sensitivity and specificity of AMII compared to MSI analysis were $6.7 \%$ and $98.0 \%$ respectively, while compared to $\mathrm{IHC}$, the sensitivity and specificity of AMII were $8.0 \%$ and $98.1 \%$ respectively (Table 1 and 2 ). Fortyeight patients $(28.1 \%)$ met one of the RBG. The sensitivity and specificity of RBG compared to $\mathrm{MSI}$ analysis were $70.0 \%$ and $82.1 \%$ respectively, while compared to $\mathrm{IHC}$, the sensitivity and specificity of RBG were $52.0 \%$ and $77.6 \%$ respectively (Table 1,2 and 3 ).

Table S2 Amsterdam II criteria and Revised Bethesda Guideline results

\begin{tabular}{ll}
\hline Types & $\begin{array}{l}\text { Number of } \\
\text { patients }(\%)\end{array}$ \\
\hline $\begin{array}{l}\text { Amsterdam II criteria } \\
\text { Negative }\end{array}$ \\
$\begin{array}{l}\text { Positive } \\
\text { Revised Bethesda Guideline } \\
\text { Negative } \\
\text { Positive }\end{array}$ \\
\hline
\end{tabular}

Table 1 Sensitivity and specificity of microsatellite instability of Amsterdam II criteria compared to the Revised Bethesda Guidelines

\begin{tabular}{|c|c|c|c|c|c|c|c|}
\hline \multicolumn{8}{|c|}{ MSI } \\
\hline Amsterdam II & MSI-H & MSI-L\&MSS & Total & $\begin{array}{l}\text { Sensitivity } \\
(\%)\end{array}$ & $\begin{array}{l}\text { Specificity } \\
(\%)\end{array}$ & $\begin{array}{l}\mathrm{ppv}^{\dagger} \\
(\%)\end{array}$ & $\begin{array}{l}\mathrm{npv}^{\ddagger} \\
(\%)\end{array}$ \\
\hline Positive & 2 & 3 & 5 & 6.7 & 98.0 & 40.0 & 84.1 \\
\hline Negative & 28 & 148 & 176 & & & & \\
\hline Total & 30 & 151 & 181 & & & & \\
\hline RBG & MSI-H & MSI-L\&MSS & Total & $\begin{array}{l}\text { Sensitivity } \\
(\%)\end{array}$ & $\begin{array}{l}\text { Specificity } \\
(\%)\end{array}$ & $\begin{array}{l}\mathbf{p p v}^{\dagger} \\
(\%)\end{array}$ & $\begin{array}{l}\mathrm{npv}^{\ddagger} \\
(\%)\end{array}$ \\
\hline Positive & 21 & 27 & 48 & 70.0 & 82.1 & 43.8 & 93.2 \\
\hline Negative & 9 & 124 & 133 & & & & \\
\hline Total & 30 & 151 & 181 & & & & \\
\hline
\end{tabular}

${ }^{\dagger} \mathrm{ppv}=$ positive predictive value, ${ }^{\ddagger} \mathrm{npv}=$ negative predictive value, $\mathrm{MSI}=$ microsatellite instability, MSI-H=microsatellite instability high, MSI-L=microsatellite instability low, MSS=microsatellite stable, RBG=Revised Bethesda Guidelines 
Table 2 Sensitivity and specificity of immunohistochemistry of Amsterdam II criteria compared to the Revised Bethesda Guidelines

\begin{tabular}{|c|c|c|c|c|c|c|c|}
\hline \multicolumn{8}{|c|}{ IHC } \\
\hline Amsterdam II & Loss & Protein expression & Total & $\begin{array}{l}\text { Sensitivity } \\
(\%)\end{array}$ & $\begin{array}{l}\text { Specificity } \\
(\%)\end{array}$ & $\begin{array}{l}\text { ppv }^{\dagger} \\
(\%)\end{array}$ & $\begin{array}{l}n p v^{\ddagger} \\
(\%)\end{array}$ \\
\hline Positive & 2 & 3 & 5 & 8.0 & 98.1 & 40.0 & 86.9 \\
\hline Negative & 23 & 153 & 176 & & & & \\
\hline Total & 25 & 156 & 181 & & & & \\
\hline RBG & Loss & Protein expression & Total & $\begin{array}{l}\text { Sensitivity } \\
(\%)\end{array}$ & $\begin{array}{l}\text { Specificity } \\
(\%)\end{array}$ & $\begin{array}{l}\operatorname{ppv}^{\dagger} \\
(\%)\end{array}$ & $\begin{array}{l}\mathrm{npv}^{\ddagger} \\
(\%)\end{array}$ \\
\hline Positive & 13 & 35 & 48 & 52.0 & 77.6 & 27.1 & 91.0 \\
\hline Negative & 12 & 121 & 133 & & & & \\
\hline Total & 25 & 156 & 181 & & & & \\
\hline
\end{tabular}

${ }^{\dagger}$ ppv=positive predictive value, ${ }^{\ddagger} n p v=$ negative predictive value, $\mathrm{IHC}=$ immunohistochemistry, RBG=Revised Bethesda Guidelines

Table 3 Correlation between Revised Bethesda Guideline and microsatellite instability analysis

\begin{tabular}{llll}
\hline \multirow{2}{*}{ Revised Bethesda Guideline } & \multicolumn{2}{c}{ MSI analysis } & \multirow{2}{*}{ OR (95\% CI) } \\
\cline { 2 - 3 } & MSI-H & MSI-L\&MSS & Ref. \\
\hline Positive & $21(70.0)$ & $27(17.9)$ & $124(82.1)$ \\
Negative & $9(30.0)$ & $10.72(4.42,25.96)^{\star}$ \\
\hline
\end{tabular}

${ }^{*} \mathrm{p}$-value<0.001 for logistic regression

$\mathrm{MSI}=$ microsatellite instability, $\mathrm{MSI}-\mathrm{H}=$ microsatellite instability high, $\mathrm{MSI}-\mathrm{L}=$ microsatellite instability low, MSS=microsatellite stable,

$\mathrm{OR}=$ odds ratio, $\mathrm{Cl}=$ confidence interval, Ref=reference

\section{Discussion}

Lynch syndrome is the most common hereditary colorectal cancer. The MMR gene mutation test ideally confirms the diagnosis. The defect of MMR protein results in frequent errors in microsatellite DNA, which are the short segments of DNA containing tandem repeats of mono-, di-, or trinucleotides, and these neoplasms are reported to cause $\mathrm{MSI}^{16}$ Besides HNPCC patients MSI profile may be found in sporadic CRC, caused by methylation-induced silencing of MLH1.,18 Thus The MSI analysis and the $\mathrm{IHC}$ were used to detect the abnormal protein results from the MMR mutation.

Although MSI is characteristic of LS tumors, it may be found in about $15.0 \%$ of unselected groups of CRC. Of this subset of MSI tumors, 20.0-25.0\% represent LS, and the other $75.0-80.0 \%$ are sporadic MSI, caused by methylation-induced silencing of MLH1. 
Indeed, the study shows that the AMII have a high specificity. Accordingly, it can be implied that the patients who have fulfilled the AMII are likely to have a MMR gene mutation. However, the AMII with a very low sensitivity may sometimes lead to misdiagnosis. Meanwhile, the sensitivity of the RBG is much better than that of the AMII. The odds ratio of positive RBG is 10.72 (95.0\% Cl=4.42, 25.96), p-value<0.001. Consequently, in order to improve the quality of screening programs for the selection of patients for molecular testing, RBG is highly recommended.

However, this diagnostic method has just been launched at the Songklanagarind Hospital, and it is still in the development stage for the MMR mutation analysis, which is considered the gold standard for diagnosing Lynch syndrome. MSI is used as the best modality to detect such an abnormality. Although approximately $10.0-15.0 \%$ of cases are sporadic with microsatellite instability due to hypermethylation of the MLH1 promotor, ${ }^{19}$ the clinical guidelines could be useful for excluding such cases. In the study, the prevalence of Lynch syndrome depended on the results of both $\mathrm{MSI}$ analysis and $\mathrm{IHC}$, which should be double positive. It can be concluded that the number of double positive samples was about $10.5 \%$. Moreover, the application of gene mutation analysis to determine accurately the prevalence of Lynch syndrome should be further investigated thoroughly.

\section{Conclusion}

The AMII had a very low sensitivity and are thus not appropriate for screening for Lynch syndrome in Southern Thai patients; nevertheless, Lynch syndrome is likely to be determined if the criteria are fulfilled. Indeed, the RBG are more practical for screening for individuals suspected of Lynch syndrome, who should then be given molecular testing. It is highly recommended that the molecular testing of both $\mathrm{MSI}$ analysis and IHC should be used with patients who meet one of the RBG criteria.

\section{Acknowledgement}

This work was supported by the Faculty of Medicine, Prince of Songkla University. The funders had no role in the study design, data collection and analysis, decision to publish, or preparation of the manuscript. The authors are also grateful to the Central Research Laboratory, Faculty of Medicine, Prince of Songkla University for the use of all its laboratory facilities.

\section{Conflict of interest}

The authors declare no conflict of interest.

\section{References}

1. Wilkins $T$, LeClair B, Smolkin M, Davies K, Thomas A, Taylor ML, et al. Screening colonoscopies by primary care physicians: a meta-analysis. Ann Fam Med 2009;7:56-62.

2. Jasperson KW, Tuohy TM, Neklason DW, Burt RW. Hereditary and familial colon cancer. Gastroenterology 2010;138: 2044-58.

3. Lynch HT, Lynch PM, Lanspa SJ, Snyder CL, Lynch JF, Boland CR. Review of the Lynch syndrome: history, molecular genetics, screening, differential diagnosis, and medicolegal ramifications. Clin Genet 2009;76:1-18.

4. Lindor NM, Petersen GM, Hadley DW, Kinney AY, Miesfeldt S, $\mathrm{Lu} \mathrm{KH}$, et al. Recommendations for the care of individuals with an inherited predisposition to Lynch syndrome: a systematic review. JAMA 2006;296:1507-17.

5. Wu Y, Berends MJ, Mensink RG, Kempinga C, Sijmons RH, van Der Zee AG, et al. Association of hereditary nonpolyposis colorectal cancer-related tumors displaying low microsatellite instability with MSH6 Germline mutations. Am J Hum Genet 1999;65:1291-8.

6. Lanza G, Gafà R, Maestri I, Santini A, Matteuzzi M, Cavazzini L. Immunohistochemical pattern of MLH1/MSH2 expression is related to clinical and pathological features in colorectal adenocarcinomas with microsatellite instability. Mod Pathol 2002;15:741-9. 
7. Peltomaki $\mathrm{P}$, Vasen $\mathrm{H}$. Mutations associated with HNPCC predisposition -- Update of ICG-HNPCC/NSiGHT mutation database. Dis Markers 2004;20:269-76.

8. Barnetson RA, Tenesa A, Farrington SM, Nicholl ID, Cetnarskyj R, Porteous ME, et al. Identification and survival of carriers of mutations in DNA mismatch-repair genes in colon cancer. N Engl J Med 2006;354:2751-63.

9. Umar A, Boland CR, Terdiman JP, Syngal S, de la Chapelle A, Rüschoff J, et al. Revised Bethesda Guidelines for hereditary nonpolyposis colorectal cancer (Lynch syndrome) and microsatellite instability. J Natl Cancer Inst 2004;96: 261-8.

10. Hampel H, Frankel WL, Martin E, Arnold M, Khanduja K, Kuebler $\mathrm{P}$, et al. Screening for the Lynch syndrome (hereditary nonpolyposis colorectal cancer). N Engl J Med 2005;352: 1851-60.

11. Hampel H, Frankel WL, Martin E, Arnold M, Khanduja K, Kuebler $\mathrm{P}$, et al. Feasibility of screening for Lynch syndrome among patients with colorectal cancer. J Clin Oncol 2008;26: 5783-8.

12. Moreira L, Balaguer F, Lindor N, de la Chapelle A, Hampel H, Aaltonen LA, et al. Identification of Lynch syndrome among patients with colorectal cancer. JAMA 2012;308:1555-65.

13. Tranø G, Sjursen W, Wasmuth HH, Hofsli E, Vatten LJ. Performance of clinical guidelines compared with molecular tumour screening methods in identifying possible Lynch syndrome among colorectal cancer patients: a Norwegian population-based study. Br J Cancer 2010;102:482-8.

14. Chang SC, Lin PC, Yang SH, Wang HS, Liang WY, Lin JK. Taiwan hospital-based detection of Lynch syndrome distinguishes 2 types of microsatellite instabilities in colorectal cancers. Surgery 2010;147:720-8.

15. Vasen HF1, Möslein G, Alonso A, Bernstein I, Bertario L, Blanco I, et al. Guidelines for the clinical management of Lynch syndrome (hereditary non-polyposis cancer). J Med Genet 2007;44:353-62.

16. Boland CR, Thibodeau SN, Hamilton SR, Sidransky D, Eshleman JR, Burt RW, et al. A National Cancer Institute Workshop on Microsatellite Instability for cancer detection and familial predisposition: development of international criteria for the determination of microsatellite instability in colorectal cancer. Cancer Res 1998;58:5248-57.

17. Aaltonen LA, Salovaara R, Kristo P, Canzian F, Hemminki A, Peltomäki $\mathrm{P}$, et al. Incidence of hereditary nonpolyposis colorectal cancer and the feasibility of molecular screening for the disease. N Engl J Med 1998;338:1481-7.

18. Loukola $A$, Eklin $K$, Laiho $P$, Salovaara $R$, Kristo $P$, Järvinen $\mathrm{H}$, et al. Microsatellite marker analysis in screening for hereditary nonpolyposis colorectal cancer (HNPCC). Cancer Res 2001;61:4545-9.

19. Herman JG, Umar A, Polyak K, Graff JR, Ahuja N, Issa JP, et al. Incidence and functional consequences of hMLH1 promoter hypermethylation in colorectal carcinoma. Proc Natl Acad Sci U S A 1998;95:6870-5. 